Published in final edited form as:

Cogn Behav Pract. 2012 January 5; 19(2): 265-276. doi:10.1016/j.cbpra.2010.12.003.

\title{
Mindfulness in the Treatment of Suicidal Individuals
}

\author{
Jason B. Luoma \\ Portland Psychotherapy Clinic, Research, \& Training Center \\ Jennifer L. Villatte \\ University of Nevada, Reno
}

\begin{abstract}
Suicidal behavior is exhibited by a diverse population of individuals and spans many diagnostic categories. In order to develop effective prevention and treatment programs, it is important to identify transdiagnostic processes that impact the many pathways to suicidality, are amenable to intervention, and affect clinical outcomes when modified. A growing body of data suggests that experiential avoidance, or the tendency to escape or avoid unwanted psychological experiences, even when such efforts cause harm, may represent one such universal process. This article reviews theory and evidence that support mindfulness and psychological acceptance as a means to target experiential avoidance in suicidal clients and thereby reduce the risk of suicide. The article also provides two case examples of the application of mindfulness to suicidality and discusses how mindfulness may help clinicians in managing the stress associated with treating suicidal clients.
\end{abstract}

\section{Keywords}

suicide; acceptance; mindfulness; case study; treatment

One of the most startling facts about suicide is how common suicidal thoughts, urges, and behaviors are. Even the rarest outcome of suicidal behavior, completed suicide, still manages to be the manner of death for 1 in every 71 people in the United States (Heron, Hoyert, Murphy, \& Xu, 2009). Suicidality is not associated with only a narrow set of syndromes or diagnoses, but rather occurs at an increased frequency across a large range of psychiatric diagnoses, as well as among those without any diagnosable conditions (Chiles \& Strosahl, 2005; Williams, Duggan, Crane, \& Fennell, 2005b). One of the biggest challenges in developing effective clinical intervention strategies is the number of pathways that can lead to suicidal behavior (Bertolote, Fleischmann, De Leo, \& Wasserman, 2004), including substance abuse (Mean, Righini, Narring, Jeannin, \& Michaud, 2005), affective disorders (Moscicki, 2001), anxiety disorders (Sareen, Houlahan, Cox, \& Asmundson, 2005), thought disorders (Siris, 2001), problems in social relationships (Helliwell, 2007), and physical health problems (e.g., Tang \& Crane, 2006).

In contrast to more traditional suicide treatment models that see suicidality as a symptom of a diagnosis and assume that it will resolve if the diagnostic condition is treated (Jobes, 2006), we believe that it is important to address suicidality directly as a primary target of concern and to identify transdiagnostic processes that cut across the many different diagnostic conditions associated with suicidal behavior. The assumption that suicidality will resolve with the resolution of an associated diagnostic condition may result in researchers

(C) 2011 Association for Behavioral and Cognitive Therapies. Published by Elsevier Ltd. All rights reserved

Address correspondence to Jason B. Luoma, Ph.D., Portland Psychotherapy Clinic, Research, \& Training Center, 5324 NE 12th Ave., Portland, OR 97211; jbluoma@gmail.com.. 
and clinicians missing important etiological and maintaning factors for suicidal behavior itself, perhaps resulting in suboptimal treatment or increased risk of reemergence of suicidality. In order to be clinically useful, such transdiagnostic processes must work with individuals on most of the pathways to suicide, be amenable to intervention, and affect clinical outcomes when they are modified. A growing body of evidence suggests that experiential avoidance, that is, the tendency to escape or avoid unwanted thoughts, emotions, memories, and sensations, even when doing so is futile or causes harm (Hayes, Wilson, Gifford, Follette, \& Strosahl, 1996), may be one such core common process. Experiential avoidance overlaps with closely related concepts that have been associated with suicidal behavior, including lack of distress tolerance (Linehan, 1993), cognitive and emotional suppression (Najmi, Wegner, \& Nock, 2007), and emotion/avoidance-focused coping (Edwards \& Holden, 2001). A recent meta-analysis (Hayes, Luoma, Bond, Masuda, \& Lillis, 2006) showed that experiential avoidance accounts for as much as $16 \%$ to $25 \%$ of the variance in behavioral health problems generally, including those identified as pathways to suicidality.

Experiential avoidance is not merely a predictor of psychological problems related to suicidality; suicide can be thought of as its most extreme expression (Chiles \& Strosahl, 2005). When all other coping strategies fail, those who suffer may look for the ultimate escape from seemingly intolerable pain. A number of sources of theorizing and evidence lead to the conclusion that suicidal behavior serves as an attempt to escape or avoid intolerable psychological experiences, including psychological pain ("psychache"; Shneidman, 1993), awareness of aversive self-evaluations (Baumeister, 1990), and a psychological perspective wherein the current situation appears hopeless and solutions to problems appear to be remote or absent (Beck, Brown, Berchick, Stewart, \& Steer, 1990; M. Williams, 2001). A study by Baumeister (1990) found that the majority of suicide notes describe escape from emotional pain as the desired function of suicide attempts. Nonlethal forms of deliberate self-harm also frequently serve the function of escaping or avoiding painful emotional experience (Chapman, Gratz, \& Brown, 2006). In addition, college students who engage in deliberate self-harm use emotionally avoidant coping styles more often than students who do not self-injure (Andover, Pepper, \& Gibb, 2006).

A number of studies have shown that interventions focused on increasing clients' mindfulness of psychological events can reduce experiential avoidance (Hayes et al., 2006), suggesting that mindfulness may be a promising alternative to suicidal behavior as a means of coping with seemingly intractable pain. In this article we review the theory and data that support the idea that mindfulness may be a means to target the common core process of experiential avoidance. We also describe the application of mindfulness to the treatment of suicidal clients and provide two case examples.

\section{Summary of Theory and Research}

Mindfulness has been a part of Western and Eastern spiritual traditions for millennia. However, mindfulness has only recently been incorporated into psychotherapy practice and has only very recently begun to be studied from scientific perspective. As with most common language terms that point to psychological phenomena, mindfulness is a relatively loosely defined concept, with authors proposing a variety of definitions (Bishop et al., 2004; Hayes \& Shenk, 2004; Siegel, Germer, \& Olendzki, 2009). Mindfulness has been described as a technique, a set of psychological processes, and as an outcome (Hayes \& Plumb, 2007). While the technique of mindfulness meditation is one way to develop mindfulness, we believe that focusing on mindfulness as a psychological process allows for more flexibility on the part of a therapist working with a suicidal client and more precise guidance on how to implement mindfulness interventions in challenging clinical situations. Below, we describe a 
model of mindfulness as a psychological process, discuss how mindfulness may mitigate several factors that have been shown to contribute to suicidal behavior, and, finally, provide examples of the application of mindfulness principles in practice with suicidal clients.

\section{Mindfulness in Psychotherapy Practice}

We will not attempt to create yet another definition of mindfulness or attempt to force a consensus from the disparate views of mindfulness. Instead, we see mindfulness as a more generic concept that overlaps highly with four psychological processes that have been described in Acceptance and Commitment Therapy (ACT; Hayes \& Plumb, 2007; Hayes \& Shenk, 2004). According to this model, mindfulness is composed of four distinct, yet overlapping processes: contact with the present moment, psychological acceptance, cognitive defusion, and self as context. Our rationale for focusing on these more basic processes is two-fold. First, we believe that it is important to not mistake lay terms for technically precise terms. While the processes we outline below are not technical terms, they are middle-level terms that allow us to link clinical language to the more precise language of behavior analysis and Relational Frame Theory (Hayes, Barnes-Holmes, \& Roche, 2001), the theories that underlie ACT. The second reason for discussing four separate processes instead of a more general concept of mindfulness is that we believe that parsing up mindfulness in this manner allows for greater flexibility and precision in its clinical application. Practitioners may more easily assess specific repertoire deficits related to mindfulness and may more precisely select techniques to mitigate these deficits. The greater range of techniques beyond formal mindfulness meditation can also help therapists to foster mindfulness in individuals who find formal meditation practice too difficult or who lack motivation for regular practice. In addition, a growing body of data from experimental psychopathology studies, therapy analogue studies, and mediational analyses support the independent contribution of these four processes to positive clinical outcomes (Levin, Hayes, \& Vilardaga, 2008).

\section{Contact With the Present}

As thinking creatures, we spend so much of our time living inside mental constructions of the future and past that we begin to lose access to our nonconceptual, direct, and current experience. Suicidal individuals, in particular, may ruminate for long periods of time about past failures or anxiously worry about future events. A person who is suicidal may feel that the pain they feel today is inescapable, constant, and extends indefinitely into a conceptual future. Suicide becomes an appealing option for solving what appears to be an intolerable problem. Rather than being caught up in a constructed future or past, mindfulness promotes ongoing, nonjudgmental contact with psychological and environmental events as they occur (i.e., present-moment awareness; Luoma, Hayes, \& Walser, 2007). Contact with the present moment focuses on the ongoing, flexible awareness of one's direct, physical and sensory experience, so that one can describe and note events without getting caught up in unhelpful comparisons, evaluations, or get stuck in the future or past. Such present-moment awareness disrupts worry and ruminative processes (Jain et al., 2007), allowing for more flexible and adaptive responses to life's current challenges and greater sensitivity to experienced feedback about the workability of problem-solving efforts.

\section{Psychological Acceptance}

Due to our ability to remember the past and to consider futures that have not yet happened, there is no situation or circumstance where we can completely escape psychological pain. As self-aware beings, we turn our own thoughts and feelings into a problem that must be solved before a life worth living is possible. Suicidal behavior can be thought of as a problem-solving attempt aimed at escape from seemingly intolerable emotional pain. 
Suicidal behavior is often reinforced by short-term escape from emotional pain and changes in the environment that elicit painful experiences. Unfortunately, the promise of immediate relief from suffering associated with suicidal behavior and thinking can distract from efforts aimed at improving suicidal clients' lives over the long term, keeping them locked in a cycle of unnecessary suffering. As an alternative to experiential avoidance, mindfulness promotes psychological acceptance, the active and intentional embrace of the psychological events occasioned by one's history, without unnecessary attempts to alter or remove them (Hayes et al., 2006). Acceptance of one's own history and current thoughts and feelings allows the freedom and flexibility to move toward a valued, meaningful life even in the presence of terrible hardship.

\section{Cognitive Defusion}

Humans tend to get caught up in the content of their thinking, such that literal, evaluative thought dominates over other sources of behavior regulation. This is especially true of the uniquely human behavior of suicide, which emerges out of an ability to contemplate a future where the cessation of self-awareness allows escape from suffering (Hayes, 1992). Suicidal thinking often tends to be relatively rigid and dichotomous with a predominance of right/ wrong and good/bad evaluation (Neuringer \& Lettieri, 1971). The thinking of suicidal individuals tends to be fatalistic and passive, waiting for change to occur or relying on change to be instigated by others (Pollock \& Williams, 2004). Rather than directly trying to change the content, frequency, or situational specificity of this thinking, the goal of cognitive defusion is to disrupt the problematic functions of thinking through creating nonliteral contexts in which a person observes the active, ongoing process of thinking, rather than merely experiencing the world as structured through thought. Similar concepts in the mindfulness literature include decentering (Fresco et al., 2007) or nonconceptual awareness (Brown, Ryan, \& Creswell, 2007). Cognitive defusion suggests that rigid suicidal thinking is not an enemy that needs to be eliminated, but rather that suicidal individuals spend too much time "in" their thoughts or "looking from" their thoughts rather than simply observing the process of thinking and returning to their experience in the present moment. Creating this nonliteral context loosens the thought-action relationship, resulting in more flexible responding to current contingencies, less control by avoidance-oriented short-term goals, and the possibility of greater influence by longer-term goals and values in decision making (Hesser, Westin, Hayes, \& Andersson, 2009).

\section{Self as Context}

Through a largely unintentional social training process, we learn to generate coherent stories about ourselves that seem to describe who we are and explain and justify our actions; we develop a conceptualized self (Luoma et al., 2007). In the case of individuals who are suicidal, this conceptualized self is often very negative, with suicidal individuals often seeing themselves as broken, damaged, or hopeless. Persistent observation of thinking, as well as other mindfulness techniques, tends to generate contact with a transcendent sense of self that is distinct from the content of one's experience. Mindfulness of thinking, rather than directly challenging the content of a person's life story or self concept, helps clients experience a sense of self that is larger than their story and more like a psychological perspective or conscious location from which all events are experienced. This can reduce attachment to a conceptualized self, thus opening up new avenues of living that are different than those in the past.

\section{Mindfulness Meditation as the Prototype}

Mindfulness meditation, as the prototypical mindfulness technique, illustrates the application of all four of these processes. Mindfulness meditation involves contacting the present moment; for example, the practitioner may be instructed to pay attention "on 
purpose, in the present moment ... to the unfolding of experience moment to moment" (Kabat-Zinn, 2003, p. 145). Acceptance is promoted through the intention to nonjudgmentally accept, allow, and even embrace all that enters one's awareness. Emotions, sensations, thoughts, urges, and memories are allowed to come and go without resistance. Typically, mindfulness meditation instructions describe how to respond to thoughts that arise. While the particulars vary, instructions typically foster defusion: dispassionately observing thinking, seeing thoughts as thoughts, rather than what they say they are, and simply allowing thoughts to come and go without holding onto them. Finally, mindfulness meditators persistently adopt a stance of an observer of their experience that allows contact with an experience of being a conscious, boundaryless "I" (Hayes, 1984) that is distinct from the content of experience-self as context. While all four of these mindfulness processes can be found in formal meditation practice, they can also be trained more or less separately through a variety of experiential methods that focus more strongly on one process or another.

\section{Mindfulness and Valued Action}

A focus on helping clients to articulate their values and take concrete action toward longerterm life goals may also be a useful complement to the development of mindfulness in suicidal clients. Suicidal individuals are typically caught up in immediate, avoidanceoriented goals while their ability to consider longer-term goals or life values is absent or restricted. Mindfulness has the potential to help clients step back from habitual patterns of responding and allow them to bring their longer-term goals and values to bear on life choices. In addition, the identification of values and hopes for one's life can provide a context that dignifies the hard work of acceptance and mindfulness. For example, mindfulness and acceptance might be framed as a means to enable movement toward deeper and closer friendships through allowing a client to compassionately hold experiences like hurt or rejection that might otherwise derail them. Two therapies that have been applied to suicidality, ACT and Dialectical Behavior Therapy (DBT; Linehan, 1993), both include a focus on building positive repertoires of behavior linked to life values and goals, in addition to their focus on mindfulness and acceptance. We suggest that it may be important to consider longer-term life directions and values as part of the larger context of mindfulness in working with suicidal clients.

\section{How Mindfulness Might Mitigate Suicidal Behavior}

A small, yet growing body of theory and data on the nature of suicidality, as well as empirical evidence on the impact of mindfulness-based interventions for suicidality, converge to suggest that mindfulness may be an effective way to mitigate the factors contributing to suicidal behavior. At least two treatment packages that include a strong focus on mindfulness, namely DBT and Mindfulness-Based Cognitive Therapy (MBCT; Segal, Williams, \& Teasdale, 2002), have already shown efficacy across multiple studies in relation to suicidal behavior. DBT has been shown to reduce number of suicide attempts, days hospitalized for suicidal ideation, and medical risks associated with self-injurious and suicidal behavior compared to community treatment by experts (Linehan, Armstrong, Suarez, Allman, \& Heard, 1991; Linehan et al., 2006). Mindfulness-based interventions have also been shown to result in large reductions in depression (Hofmann, Sawyer, Witt, \& Oh, 2010), a common context for suicidal ideation and behavior (Beautrais et al., 1996). More specifically, MBCT has been shown to reduce depressive relapse for people with recurrent depression (Teasdale et al., 2000) and reduce residual depressive symptoms in individuals in recovery following an episode of suicidal depression (Crane et al., 2008).

Indirect support for the use of mindfulness with suicidal clients comes from evidence showing that interventions aimed at increasing mindfulness and acceptance of psychological 
events reduce experiential avoidance, and that changes in experiential avoidance relate to changes in many of the psychological problems that are predictive of suicidality, including substance abuse, depression, anxiety, chronic pain, and psychotic symptoms (Hayes et al., 2006). Of the available mindfulness-based therapies, ACT has demonstrated across a number of studies that it is effective in reducing experiential avoidance (Hayes et al., 2006) and that changes in experiential avoidance mediate outcomes from ACT (Levin et al., 2008). While it seems likely that other therapies including a strong focus on mindfulness (such as DBT and MBCT) might also have much of their effect through changes in experiential avoidance or other mindfulness processes, these mediational analyses have not been conducted.

While the bodies of research reviewed above provide some support for the idea that mindfulness may be useful in preventing suicidal behavior, stronger support would come from data showing that changes in mindfulness processes mediate change in suicidal behavior or from experimental psychopathology studies demonstrating the effect of specific mindfulness processes on suicidal thinking or behavior. In the absence of such data, we propose that clinicians be cautious about the utilization of mindfulness as a stand-alone intervention with suicidal clients and consider more established interventions such as those reviewed in some of the other articles in this special series. Below, we outline research on three psychological processes that have been shown to contribute to suicidal behavior and describe how we believe mindfulness might help to mitigate their impact. Each of these processes below can be conceptualized as either a result of experiential avoidance or as a kind of experiential avoidance.

\section{Overgeneral Memory and Suicidal Behavior}

Suicidal individuals, along with depressed individuals, evidence a phenomenon called overgeneral memory, in which they experience difficulty recalling specific episodes and details from their autobiographical memory (Evans, Williams, O'Loughlin, \& Howells, 1992; Williams \& Broadbent, 1986). The inability to recall specific life events in turn contributes to the poor problem-solving abilities of suicidal individuals that have been repeatedly demonstrated in the literature (Williams, Barnhofer, Crane, \& Beck, 2005a). Overgeneral memory is hypothesized to be due, at least in part, by a rapid, habitual tendency among suicidal individuals to avoid or suppress specific autobiographical memories due to associated negative affect (Williams, Teasdale, Segal, \& Soulsby, 2000).

The idea that mindfulness-based interventions could reduce overgeneral memory in suicidal persons is bolstered by a study showing that MBCT reduces overgeneral autobiographical memory in formerly depressed patients (Williams et al., 2000). These authors suggest that the focus in mindfulness on contacting the present moment and regularly noticing specific aspects of one's experience and environment might lead to more specific encoding of autobiographical information. Additionally, the focus on accepting private events without trying to change or evaluate them could reduce the tendency to suppress autobiographical recall in the service of reducing negative affect. As a result of improving the retrieval of specific autobiographical events, problem-solving behavior should be improved among suicidal people, thus reducing the risk of suicide as an attempted solution to intractable suffering.

\section{Thought Suppression and Suicidal Behavior}

Suicidal individuals at their most despairing often suffer from intrusive mental images of suicide (Holmes, Crane, Fennell, \& Williams, 2007) and attempt to suppress them from awareness (Pettit et al., 2009). Unfortunately, a range of studies has shown that attempting to suppress intrusive thoughts tends to result in an increase in the intensity and frequency of 
those very thoughts, as well as increases in the intensity of negative emotions accompanying those thoughts (Roemer \& Borkovec, 1994). Cross-sectional studies with suicidal populations have shown that the tendency to suppress unwanted thoughts is associated with suicidal ideation (Pettit et al.) and that thought suppression mediates the relation between negative emotionality or emotional reactivity and suicidal ideation (Lynch, Cheavens, Morse, \& Rosenthal, 2004; Najmi et al., 2007). One longitudinal study showed that suppression of suicidal thoughts predicts increased suicidal thinking over time, even after controlling for depressive symptoms (Pettit et al.). Together these results indicate that suicidal individuals tend to suppress intrusive thoughts of suicide, resulting in the engagement of an ironic process that serves to maintain suicidal thinking over time.

While the goal of acceptance in mindfulness is not the reduction of negative or distressing thoughts, paradoxically, mindfulness does appear to result in a reduction of their frequency (Frewen, Evans, Maraj, Dozois, \& Partridge, 2008). Cognitive defusion, or the ability to observe the process of thinking rather than be entangled in cognitive activity, may help individuals observe their thinking with greater equanimity and reduce the need to suppress such thoughts, thus short-circuiting the ironic effects of thought suppression (Hepburn et al., 2009).

\section{Self-Critical Brooding and Escape From Self-Awareness}

Suicidal behavior can arise from attempts to escape aversive and self-critical self-awareness, including perceived failures to live up to self and others' standards (Crane et al., 2008). In a social psychological view of suicide, Baumeister (1990) argued that suicide attempts result from a desire to alleviate aversive awareness of negative self-evaluations relating to perceived failures and inadequacies and accompanying negative affect. In this model, as efforts to avoid painful self-awareness fail, suicide becomes more attractive as an option. Support for this theory comes from evidence that individuals who have previously been suicidal retain a tendency to engage in negative self-evaluative thinking and that this thinking predicts poorer outcomes. For example, Crane, Barnhofer, and Williams (2007) examined three groups of people who had previously been depressed: one group had previously attempted suicide, one had suicidal ideation, and one had no previous suicidal ideation. Those with a previous suicide attempt showed higher levels of brooding, a form of critical self-focused attention that predicts poor depression outcomes. Individuals with a history of suicidal ideation and those with a history of previous suicide attempts showed lower levels of reflection, a form of self-focused attention similar to focused problemsolving that predicts better depression outcomes. In summary, it appears that negative selfcritical rumination is prevalent in suicidal individuals and avoidance of this experience may be part of what motivates suicidal behavior.

Several aspects of mindfulness may help reduce suicidal behavior motivated by escape from aversive self-awareness. One focus of mindfulness is the awareness of a transcendent sense of self that is separate from the content of one's experience, that is, the experience of an "observer self" or "self as context." Seeing oneself ("I") as separate from the content of one's self-concept (e.g., "I am bad") can help reduce the impact of negative, self-evaluative thinking. In other words, a person who is able to contact a sense of self as a conscious observer might respond to negative self-evaluations (e.g., "I am broken") as more mental content and not something that needs to be invested in or fought with. Mindfulness also fosters the observation of the process of mental activity, such that self-critical and judgmental thoughts are observed more as passing mental events, rather than as indicating something enduring about the self that demands a response. Similarly, the development of openness and compassionate acceptance of one's own painful self-evaluations should reduce the need to suppress that thinking, thus short-circuiting ironic processes that maintain it. Finally, the development of self-compassion (Gilbert \& Procter, 2006; Neff, 2009) through 
mindfulness practice may help neutralize the harmful effects of self-critical thinking on depressive mood and give individuals alternatives to escape from self-awareness through suicidal behavior.

\section{Application of Mindfulness With Suicidal Clients}

Below we outline the application of the four mindfulness and acceptance processes described above to two cases, one involving chronic suicidal ideation and one with more transient suicidal ideation. Viewing mindfulness as comprised of four psychological processes allows for a broader and more flexible application of mindfulness to the clinical situation, beyond the formal practice of mindfulness. Theory can guide the creation of exercises or metaphors that fit a client's particular life history or situation. For clients who don't like to close their eyes, a therapist might do more active exercises. For clients who are more visual, exercises can include imagery. For clients who find formal mindfulness practice aversive or have a hard time concentrating, mindfulness can be introduced in very small doses or using easier exercises first, before progressing to exercises the client finds more difficult. Through the flexible application of present-moment awareness, acceptance, defusion, and self-as-context processes, mindfulness is encountered and engaged, even without necessarily sitting down. The cases presented below were treated largely from an ACT perspective, a literature that alone has hundreds of exercises, metaphors, and teaching stories that have already been created to target various aspects of mindfulness.

\section{Anne}

Anne was a 22-year-old single white female who was referred to a psychology department DBT clinic by a therapist in the community who felt she did not have the resources to manage Anne's intense emotional dysregulation, deliberate self-injury, and suicide risk. The DBT clinic had a 4-month wait list at the time of the referral, so she was referred to the ACT treatment team to discuss alternative treatment options while she waited for an opening. After explaining the ACT approach and discussing the potential risks and benefits of this treatment, Anne agreed to ACT while on the waiting list. To prevent therapists from unintentionally reinforcing suicidality as a means of obtaining emotional and instrumental support, ACT (like DBT) aims to evoke and reinforce expression of distress and requests for help prior to expressions of suicidal thoughts and urges (see Chiles \& Strosahl, 2005). Anne agreed to a safety plan that emphasized therapist involvement prior to self-injurious or suicidal acts and relied on the local crisis and medical centers in the event of an occurrence of suicidal behavior.

As is common for multiproblem, chronically suicidal clients, Anne met criteria for multiple Axis I and II disorders, including posttraumatic stress disorder, bulimia, borderline personality disorder, and cocaine and alcohol abuse. Anne had been struggling with persistent suicidal thoughts and urges since she was a teenager. While growing up, she suffered severe physical and sexual abuse from an alcoholic father and was frequently relied on to care for her younger siblings. She dropped out of school at age 15 and has had difficulty keeping a job ever since. When she was referred for therapy, she had no contact with her family and was living alone with no friends and little social support. She engaged in a range of destructive behaviors, including bingeing and purging, drug and alcohol abuse, and deliberate self-injury in the form of cutting and burning. Anne had attempted suicide three times in the past 2 years. She stated that she already felt dead inside and could identify no reasons to live.

Therapy began with a functional analysis of Anne's current psychological distress, the contexts which occasioned it, and her typical ways of coping (Luoma et al., 2007, pp. 2736). Several sessions were spent examining the workability of these coping strategies with 
the conclusion that many of the behaviors that were causing Anne harm were logical attempts to rid herself of the awareness of her agonizing past and the hopeless future she had constructed. It was jointly concluded that the only threats in her current environment were her own thoughts and feelings, and that her attempts to avoid or escape them were causing additional and unnecessary harm. It was painful for both therapist and client to acknowledge how much of Anne's life was lost in the war to conquer her own mind, and that anguish provided motivation to find a new approach to living with her traumatic history.

Recognizing that the current solutions weren't really solving anything, therapy focused on exploring the possibility that the problems themselves might be reconsidered. It was at this point that mindfulness was introduced as an alternative to Anne's constant focus on changing, reducing, or eliminating unpleasant memories, sensations, and emotions.

Anne had almost no awareness of her body or current feelings and sensations, as these evoked traumatic memories and were primary targets of experiential avoidance. As a result, she was alexithymic and had a very unstable sense of self, fluctuating between a sense of emptiness and a conceptualized self as unlovable, damaged, and irredeemably flawed. These patterns suggested a deficit in Anne's ability to remain in contact with the present moment and fusion with a negative self-concept, resulting in a lack of self-awareness and in instability in her sense of self. Work on contacting the present moment began with very brief moments of observing the sounds around her, then the sensations she experienced while washing her hands or sipping a hot beverage. This mindful present-focused attention was first coached with very brief in-session exercises followed by out-of-session practice. As Anne became more adept at focusing her attention on the present, the therapist introduced eyes-closed mindfulness exercises like observing the breath or scanning the body and noticing sensations that were present, such as muscle tension, fatigue, or tactile pressure. These body-focused mindfulness exercises were particularly difficult for Anne due to the tendency for these to elicit trauma-related anxiety and imagery, so acceptance techniques were incorporated into the exercises to facilitate her willingness to engage in the process. For example, she was asked to notice any resistance or fear that arose when focusing on her body and to see if she was willing to breathe in that feeling with her next inhalation, neither holding it in nor forcing it out, but allowing it to move though her with the natural movement of the breath. The taking in and making space for difficult psychological events acted as a physical metaphor for acceptance of one's past and current pain in the service of building a life worth living.

Clients like Anne are often convinced that fully contacting their thoughts, emotions, and memories will literally overwhelm them and result in damage to or annihilation of the self. Mindfulness techniques that focus on meta-awareness help to foster a stable sense of self that transcends the content of one's experience and provides a safe context in which to confront deep emotional pain. This sense of self as a context for all of experience or constant perspective from which everything is experienced can provide contact with an aspect of self that has remained constant and unchanged throughout life and cannot be damaged by real or perceived failures or traumas. With Anne, an exercise called the Observer Exercise (Hayes, Strosahl, \& Wilson, 1999, pp. 193) was used to introduce Anne to this stable, continuous self as context. The exercise began by inducing a state of relaxed focus and gradually directing Anne's attention to different moments in her life and domains with which she struggled. As she observed her thoughts, memories, beliefs, and feelings, she was also directed to notice who was noticing these events. Questions such as, "Can you sense that the same person that was there then, experiencing the world through your eyes, is here now?" point to the continuity of self across time and situations. Comments like, "If you are the one noticing this feeling, you mustn't be this feeling" establish a sense of self that observes, but is distinct from psychological experiences. Through perspective taking exercises like these, Anne came to sense herself as more than her body, her history, or her thoughts and feelings, 
but rather as a unique, unchanging, ever-present context for all of life's experiences. Development of contact with this sense of self can also facilitate other mindfulness processes, in Anne's case through increasing her willingness to confront and carry the pain of her past (i.e., acceptance) and increasing contact with a sense of self that can choose and act intentionally toward longer-term valued ends with all of her painful and difficult history and automatic reactions, rather than in mindless reaction to them.

During the first 8 weeks of therapy, Anne's scores climbed steadily on several facets of the Five Factor Mindfulness Questionnaire (Baer, Smith, Hopkins, Krietemeyer, \& Toney, 2006), including the Nonjudge, Nonreact, and Observe subscales. At this point, work on identifying Anne's values was instituted in order to help her develop a consistent sense of direction and purpose for her life and to help provide a larger context for emotional acceptance work (Dahl, Plumb, Stewart, \& Lundgren, 2009). As is often the case for clients with chaotic lives and complex, traumatic histories, identifying valued direction is not as straightforward as asking questions like "What are your values?" and systematically drawing out a person's already identified values and life goals. As Anne had directly stated that her life had no meaning or purpose and she could not identify any specific reasons to live, the therapist began by asking questions like, "What if your life could be about something other than trying to get away from your past? What if our work could be about letting go of this struggle so that you have the freedom and flexibility to choose what you want your life to be about, even if you have no idea what that would look like yet?" Alongside this process of values development, Anne's ability to practice nonjudgmental awareness of the present moment grew and she began to notice small moments where she experienced pleasure, satisfaction, and meaning. Over time her ability to be in the present moment with these questions about meaning and positive direction brought her behavior more under the influence of positive reinforcement, rather than her more typical patterns of negative reinforcement in the form of avoidance and escape. In time, she realized that she cared very much about trust and intimacy with her siblings and friends and found great satisfaction in inspiring others to learn, which she pursued through a career in teaching and working with youth in her religious community. After several weeks of focusing on emotional acceptance in the service of creating a meaningful life based on her values, there were sharp increases in the Nonjudge and Act With Awareness subscales of the Five Factor Mindfulness Questionnaire. These scores corresponded with significant decreases in standardized measures of overall symptomatology and borderline features.

Even after Anne's suicidal thinking and self-harming behavior had greatly diminished, she would still become deeply distressed when a suicidal thought or urge unexpectedly emerged. When this happened, she would examine her life for reasons she might want to die, believing the suicidal thought or urge to be evidence of a problem she was not aware of. This would lead to rumination, increased negative affect, and greater intensity of suicidal urges. Defusion can be helpful in dealing with these conditioned thoughts and urges by seeing them for what they are instead of as the reasons and causes they claim to be (Hayes et al., 1999, pp. 163-166). For example, Anne was having a pleasant visit with her brother when she suddenly had an image of herself jumping in front of a bus while crossing the street. Though she had made great progress in improving the relationships with her siblings, she got caught up in the belief that she would never have close and satisfying relationships, which seemed to justify her sudden suicidal urges. Through in-session exercises and homework assignments focused on helping Anne to step back from her thinking and looking at her thoughts rather than from them, she was able to recognize that these disturbing images and urges were no more than her mind's familiar way of coping with family stressors. Anne found it helpful to think about these thoughts and urges as if they were text on a computer screen that automatically appeared based on her history of typing (Harris, 2009, p. 112). As she began writing the next passages in her life story, she saw that her mind would present 
her with bits of her history in an attempt to be helpful. This metaphor helped Anne to recognize that her past was no longer dictating her life story and she was able to choose what would happen next, regardless of what interpretations and suggestions appeared on her screen. Anne began to develop the ability to see suicidal thoughts as thoughts, not evidence of some deeper disturbance, and developed greater ability to refocus her attention on what was occurring in the present moment, allowing her to respond more effectively to the pleasures and challenges of spending time with her family. After 18 sessions, Anne's level of psychological distress had fallen to subclinical levels on two symptom inventories. She continued to attend biweekly therapy for 20 more weeks before deciding that she was ready to terminate treatment. At 1-year follow-up, Anne's mindfulness scores remained high and she no longer met current criteria for any psychological disorder.

\section{Mark}

Mark was a 47-year-old white male who was hospitalized following a suicide attempt via carbon monoxide poisoning. A neighbor found him unconscious in his car and Mark received medical treatment that prevented long-term neurological damage. Prior to the death of his wife and two children in a car accident 1 year previously, Mark had been a successful businessman with no history of psychological problems or treatment. Following the death of his family, he was overwhelmed with grief and guilt for not being able to prevent the accident and, in the months following their death, he stopped working, paying his bills, and taking caring of himself. He slept and ate little, rarely left the house, and eventually tried to take his own life. When he first presented for therapy shortly after his release from the hospital, he stated that he "should have died in the crash" and "didn't deserve to be happy."

Mark was not convinced that accepting the pain and guilt he was feeling would be the way out of the hell he had been living since the loss of his family. He described himself as "a dead man walking," believing that any sign of vitality or movement would indicate that he no longer remembered or cared for his family. This resulted in a kind of cognitive trap: either he had to remain miserable as a testament to his love and loss of his family, or he had to die. Therapy began by validating what his experience already told him-this was, in fact, an unwinnable scenario. Rather than increasing hopelessness, clients often find it genuinely validating when therapists acknowledge that despite their best efforts, attempts to control emotional pain have led to increased suffering. It can be deeply liberating to acknowledge the despair at having applied all one's effort, motivation, and cleverness to solving a problem in the most logical way, and ending up even deeper in the hole than when one started. The therapist's willingness to be present with Mark's despair without treating him as fragile communicated that these difficult private experiences are not barriers to feeling well, but an opportunity to practice living well in the face of unexpected and unavoidable hardship. Though Mark was skeptical that mindfulness could be an effective means of dealing with his grief, he acknowledged that nothing else was working and agreed to experiment with it in session.

Initially, Mark had great difficulty practicing any mindfulness exercise that required him to sit still with his eyes closed. He complained that he would become tired or uncomfortable and feel the urge to get up or move around, or would become distracted, think he was doing the exercise incorrectly, and lose focus. The therapist explained that these small struggles were perfect opportunities to practice acceptance and that the purpose of these exercises was not to maintain Zen-like clarity, focus, or relaxation, but to learn to experience thoughts, feelings, and urges without having to react to them. In this way, mindfulness was presented as a means of making room for the full range of psychological experiences, accepting them for what they are instead of what they claim to be, and moving forward toward one's chosen values. 
Key to the effective implementation of mindfulness is weaving the practice into daily life. This can be achieved through formal mindfulness-fostering practices, such as meditation, explicit homework focused on practicing mindfulness in everyday life (Hayes, 2005, pp. 105-115), and in-session application of mindfulness to inflexible or problematic behavior that occurs in session. Mark initially committed to brief daily homework assignments focused on bringing mindfulness to everyday activities like showering, walking, and eating. As he became more adept at sustaining attentional focus, he agreed to practice acceptance of sensations, emotions, and urges in longer exercises focused on sitting, breathing, or walking. Mark would talk with his therapist about difficulties he encountered in his home practice in real-life settings and would work on these areas in session, incorporating defusion, acceptance, and self-as-context elements as needed.

Psychological acceptance was introduced as an alternative to resignation or escape via suicide (Chiles \& Strosahl, 2005). The therapist emphasized that willingness to experience the pain in one's life (i.e., acceptance) is not the same as liking, wanting, or approving of its presence. Rather, acceptance is an active choice to embrace all aspects of one's experience in the service of living well. From this stance, Mark was helped to explore his grief as a means of contacting his values. Tough questions were asked, such as "Do you want your life to be a funeral dirge, focused on preserving the past? Or do you want to live your life in a way that honors and carries forward the love you shared with your family?" Mark began to defuse from his belief that the only way to express his love for his family was through persistent, unabated grieving and opened to the possibility of living a life outside of the impossible trap he set for himself.

Mark would often say that he wasn't strong enough to contain his overwhelming grief and he feared that if he allowed himself to think about his family, he would sink so deeply into despair that he would lose himself completely. In the eighth session, Mark expressed that he was again planning suicide. Though he was making progress in his ability to dispassionately observe less intense emotions, it appeared that Mark would benefit from being able to access a sense of self as context or observer of his experience when he contacted what felt like overwhelming grief. Metaphors such as comparing the self to the sky that is unaffected by the storms and weather events that occur within it (Harris, 2009, p. 175) were used to help him contact a sense of self that is not threatened by aversive events and psychological experiences, but provides a context or container for the events of his life. When Mark felt he was drowning in sadness and/or was convinced that his life would never again have meaning, the therapist would ask questions intended to contact self as context, such as "Are you like the storm or the sky right now?" The therapist would ask him to close his eyes and sense the self that is as vast and unchanging as the sky and to simply watch the storm of his thoughts and emotions churning within. Mark described this experience of self as being big enough to contain both the good and bad memories and emotions at the same time, much as the sky contains light even in moments when one sees only darkness. This metaphor helped Mark to take some psychological distance from difficult private events, allowing him to experience the pain of his loss without succumbing to avoidance, escape, or inaction.

Mark described the months after the accident as a never-ending flood of memories, a constant torrent of intense and overwhelming grief. He would get so caught up in these thoughts that hours would pass without him realizing it. Defusion techniques were used to help Mark get out of his mind and into the present moment. For example, a common ACT exercise called "leaves on a stream" (Luoma et al., 2007, p. 95) had Mark imagining himself sitting on the bank of a river, watching the water flow by. In this exercise, he was asked to place any thoughts, memories, or feelings he noticed on leaves and watch them float down a river. Any reactions to this process, such as wanting to keep a happy memory from floating away, were also put on leaves. At first, Mark found it difficult to identify specific thoughts 
and memories and would become frustrated when the same images would keep reappearing. With practice, he learned to observe the process of thinking, remembering, evaluating, and feeling and began to relate to the contents of his mind differently. He could observe variations in intensity, frequency, and valence and see this mental content as a series of transient psychological events rather than a true and constant representation of reality. While his thoughts and memories still evoked powerful emotions, they exerted less control over his behavior and he was able to attend to other events as well.

After 6 months of ACT, Mark had returned to work and began to reestablish relationships with friends and family, stating that he would no longer take for granted the time he had with those that mattered to him. He even made a point of spending time with his young nieces and nephews, something that was unbearable for him in the year following the death of his own children. He recently began volunteering for the Audubon Society, tending to the nature trails that he and his family enjoyed on so many occasions and guiding local groups on hikes in the mountains around their home. Though he still had moments of overwhelming grief and sadness, he stated that he no longer considered suicide a viable option and chose to live with the pain of missing his family in the service of keeping their love alive.

\section{The Mindfulness of the Clinician in Treating Suicidal Clients}

In addition to using mindfulness as an intervention with suicidal clients, mindfulness may also be helpful for the therapist working with suicidal clients who often provoke anxiety and other difficult emotions for therapists. Emotional reactions to suicidal clients tend to be more intense than with other clients (Jacoby, 2004), and often include helplessness or hopelessness, questions about professional competence, anxiety over potential lawsuits, or concerns about the professional implications of a client suicide. The often intense despair and hopelessness of suicidal clients can be difficult for a therapist to endure without emotionally distancing themselves or feeling frustrated with limited change. Unfortunately, emotional distancing from clients can lead to therapist disinterest, boredom, disinvestment, and even active dislike (Maltsberger \& Buie, 1974). Legal and ethical requirements often leave therapists in a situation where they are held responsible for the client's behavior, yet also are confronted with the reality of their limited ability to predict or control the client's behavior. Clearly, suicidal clients are often challenging for therapists.

Fortunately, mindfulness on the part of the therapist appears likely to be able to help therapists maintain flexibility in the face of such difficult situations. Therapists who can maintain a mindful posture in the face of aversive stimulation (e.g., challenging clinical situations) might be more flexible in their engagement in therapeutic tasks, less controlled by more immediate aversive experiences, and more able to take into account longer-term therapeutic goals as they manage client behavior. A number of studies have shown that mindfulness practice helps health professionals to experience less burnout and greater empathy for client situations (Krasner et al., 2009). One study even suggests that mindfulness meditation might generally lead to better therapy outcomes (Grepmair et al., 2007). Indeed, several therapies include mindfulness practice for the therapist as an essential part of practicing the therapy. DBT requires mindfulness practice on the part of therapists during weekly team consultation meetings, while MBCT holds that therapists teaching MBCT should maintain a personal mindfulness practice. ACT has traditionally included experience with applying mindfulness processes to oneself as part of therapist training and also has demonstrated that such training can result in improved psychological acceptance and reduced burnout in counselors (Hayes et al., 2004).

Therapists might practice mindfulness in relation to their clients in a variety of ways. Perhaps the most obvious would be to have a personal meditation practice. Also, therapists 
can incorporate formal mindfulness exercises into their work with suicidal clients. For example, a therapist might engage in brief mindfulness exercises just prior to sessions with suicidal clients or might begin sessions by engaging in a brief mindfulness meditation along with the client. When a therapist notices difficult personal experiences arise during a session, such as tension in the body or uncomfortable emotional reactions, he or she might briefly practice mindful awareness of his or her thoughts and feelings, or focus more intentionally on the behavior and emotions of the client.

Due to the often chaotic lives of suicidal clients, therapy can easily devolve into a haphazard focus on rapidly alternating crises, rather than focusing on long-term development of mindfulness, acceptance, and positive movement toward valued life goals. Unfortunately, rapid engagement of a problem solving set in the absence of mindful awareness and acceptance can feed the client's tendency toward experiential avoidance, even though it might seem responsive in the short term. In this situation, both client and therapist can become caught up in the fundamentally unaccepting position that the client's problems must be solved in order for the client to build a life worth living. The client him- or herself may even seem to become a problem. In these situations, mindfulness may help the therapist slow down and reside more fully in the present moment with the client as a whole person, rather than a problem. The therapist may experience more room to contact his or her longerterm values and goals relating to the client, so that these can direct the therapy, rather than short-term crisis-focused goals. Lastly, mindfulness can help the therapist to be more accepting of his or her own reactions encountered in the process of helping the client build a life worth living.

\section{Conclusion}

Although more research is needed, mindfulness appears to offer promise for those people contemplating suicide as a method to end their suffering. Encouraging preliminary evidence suggests that therapists can foster mindfulness in a relatively brief period of time and that mindfulness can affect a variety of processes thought to contribute to suicidal behavior. Through mindfulness, suicidal individuals are taught to observe the dark calculus of suicide with equanimity, cultivate kindness and self-compassion toward themselves, and to return to living each moment to its fullest. In addition to its use as a clinical intervention, mindfulness can help clinicians to respond adaptively to the stress of working with suicidal clients and maintain flexibility in challenging clinical situations. Mindful therapy involves the creation of a culture of caring and compassion (even if only a culture of two) that can benefit both therapist and client.

\section{References}

Andover MS, Pepper CM, Gibb BE. Self-mutilation and coping strategies in a college sample. Suicide \& Life-Threatening Behavior. 2006; 37:238-243. [PubMed: 17521275]

Baer RA, Smith GT, Hopkins J, Krietemeyer J, Toney L. Using self-report assessment methods to explore facets of mindfulness. Assessment. 2006; 13:27-45. [PubMed: 16443717]

Baumeister RF. Suicide as escape from self. Psychological Review. 1990; 97:90-113. [PubMed: 2408091]

Beautrais A, Joyce P, Mulder R, Fergusson D, Deavoll B, Nightingale S. Prevalence and comorbidity of mental disorders in persons making serious suicide attempts: A case control study. The American Journal of Psychiatry. 1996; 153:1009-1014. [PubMed: 8678168]

Beck AT, Brown G, Berchick RJ, Stewart BL, Steer. Relationship between hopelessness and ultimate suicide: A replication with psychiatric outpatients. The American Journal of Psychiatry. 1990; 147:190-195. [PubMed: 2278535] 
Bertolote JM, Fleischmann A, De Leo D, Wasserman D. Psychiatric diagnoses and suicide: Revisiting the evidence. Crisis: The Journal of Crisis Intervention and Suicide Prevention. 2004; 25:147-155.

Bishop SR, Lau M, Shapiro S, Carlson L, Anderson ND, Carmody J, et al. Mindfulness: A proposed operational definition. Clinical Psychology: Science and Practice. 2004; 11:230-241.

Brown KW, Ryan RM, Creswell JD. Mindfulness: Theoretical foundations and evidence for its salutary effects. Psychological Inquiry. 2007; 18:211-237.

Chapman A, Gratz K, Brown M. Solving the puzzle of deliberate self-harm: The experiential avoidance model. Behaviour Research and Therapy. 2006; 44:371-394. [PubMed: 16446150]

Chiles, JA.; Strosahl, KD. Clinical manual for assessment and treatment of suicidal patients. American Psychiatric Publishing; Arlington, VA: 2005.

Crane C, Barnhofer T, Duggan DS, Hepburn S, Fennell MV, Williams JMG. Mindfulness-based cognitive therapy and self-discrepancy in recovered depressed patients with a history of depression and suicidality. Cognitive Therapy and Research. 2008; 32:775-787.

Crane C, Barnhofer T, Williams JMG. Reflection, brooding, and suicidality: A preliminary study of different types of rumination in individuals with a history of major depression. The British Journal of Clinical Psychology. 2007; 46:497-504. [PubMed: 17678576]

Dahl, JC.; Plumb, J.; Stewart, I.; Lundgren, T. The art and science of valuing in psychotherapy: Helping clients discover, explore, and commit to valued action using acceptance and commitment therapy. New Harbinger; Oakland, CA: 2009.

Edwards MJ, Holden RR. Coping, meaning in life, and suicidal manifestations: Examining gender differences. Journal of Clinical Psychology. 2001; 57:1517-1534. [PubMed: 11745593]

Evans J, Williams JM, O'Loughlin S, Howells K. Autobiographical memory and problem-solving strategies of parasuicide patients. Psychological Medicine. 1992; 22:399-405. [PubMed: 1615107]

Fresco DM, Moore MT, van Dulmen MHM, Segal ZV, Ma SH, Teasdale JD, et al. Initial psychometric properties of the Experiences Questionnaire: Validation of a self-report measure of decentering. Behavior Therapy. 2007; 38:234-246. [PubMed: 17697849]

Frewen PA, Evans EM, Maraj N, Dozois DJA, Partridge K. Letting go: Mindfulness and negative automatic thinking. Cognitive Therapy and Research. 2008; 32:758-774.

Gilbert P, Procter S. Compassionate mind training for people with high shame and self-criticism: Overview and pilot study of a group therapy approach. Clinical Psychology \& Psychotherapy. 2006; 13:353-379.

Grepmair L, Mitterlehner F, Loew T, Bachler E, Rother W, Nickel M. Promoting mindfulness in psychotherapists in training influences the treatment results of their patients: A randomized, double-blind, controlled study. Psychotherapy and Psychosomatics. 2007; 76:332-338. [PubMed: 17917468]

Harris, R. ACT made simple. New Harbinger; Oakland, CA: 2009.

Hayes SC. Making sense of spirituality. Behaviorism. 1984; 12:99-110.

Hayes, SC. Verbal relations, time and suicide. In: Hayes, SC.; Hayes, LJ., editors. Understanding verbal relations. Context Press; Reno, NV: 1992. p. 109-118.

Hayes, SC. Get out of your mind and into your life. New Harbinger; Oakland, CA: 2005.

Hayes, SC.; Barnes-Holmes, D.; Roche, B. Relational frame theory: A post-Skinnerian account of human language and cognition. Kluwer Academic/Plenum; New York: 2001.

Hayes SC, Bissett R, Roget N, Padilla M, Kohlenberg BS, Fisher G, et al. The impact of Acceptance and Commitment Training and multicultural training on the stigmatizing attitudes and professional burnout of substance abuse counselors. Behavior Therapy. 2004; 35:821-835.

Hayes SC, Luoma JB, Bond FW, Masuda A, Lillis J. Acceptance and Commitment Therapy: Model, processes and outcomes. Behavior Research and Therapy. 2006; 44:1-25.

Hayes SC, Plumb JC. Mindfulness from the bottom up: Providing an inductive framework for understanding mindfulness processes and their application to human suffering. Psychological Inquiry. 2007; 18:242-248.

Hayes SC, Shenk C. Operationalizing mindfulness without unnecessary attachments. Clinical Psychology: Science and Practice. 2004; 11:249-254. 
Hayes, SC.; Strosahl, K.; Wilson, KG. Acceptance and commitment therapy: An experiential approach to behavior change. Guilford Press; New York: 1999.

Hayes SC, Wilson KG, Gifford EV, Follette VM, Strosahl K. Experiential avoidance and behavioral disorders: A functional dimensional approach to diagnosis and treatment. Journal of Consulting and Clinical Psychology. 1996; 64:1152-1168. [PubMed: 8991302]

Helliwell JF. Well-being and social capital: Does suicide pose a puzzle? Social Indicators Research. 2007; 81:455-496.

Hepburn SR, Crane C, Barnhofer T, Duggan DS, Fennell MJV, Williams JMG. Mindfulness-based cognitive therapy may reduce thought suppression in previously suicidal participants: Findings from a preliminary study. The British Journal of Clinical Psychology. 2009; 48:209-215. [PubMed: 19254446]

Heron M, Hoyert DL, Murphy SL, Xu J. National Vital Statistics Reports. National Vital Statistics Reports. 2009; 57:14.

Hesser H, Westin V, Hayes SC, Andersson G. Clients' in-session acceptance and cognitive defusion behaviors in acceptance-based treatment of tinnitus distress. Behaviour Research and Therapy. 2009; 47:523-528. [PubMed: 19268281]

Hofmann SG, Sawyer AT, Witt AA, Oh D. The effect of mindfulness-based therapy on anxiety and depression: a meta-analytic review. Journal of Consulting and Clinical Psychology. 2010; 78:169. [PubMed: 20350028]

Holmes EA, Crane C, Fennell MJV, Williams JMG. Imagery about suicide in depression-'Flashforwards'? Journal of Behavior Therapy and Experimental Psychiatry. 2007; 38:423-434. [PubMed: 18037390]

Jacoby AM. Negative countertransference in psychotherapy with suicidal patients. Dissertation Abstracts International: Section B: The Sciences and Engineering. 2004; 64(11-B) 2004.

Jain S, Shapiro SL, Swanick S, Roesch SC, Mills PJ, Bell I, et al. A randomized controlled trial of mindfulness meditation versus relaxation training: Effects on distress, positive states of mind, rumination, and distraction. Annals of Behavioral Medicine. 2007; 33:11-21. [PubMed: 17291166]

Jobes, DA. Managing suicidal risk: A collaborative approach. Guilford Press; New York: 2006.

Kabat-Zinn J. Mindfulness-based interventions in context: Past, present, and future. Clinical Psychology: Science and Practice. 2003; 10:144-156.

Krasner MS, Epstein RM, Beckman H, Suchman AL, Chapman B, Mooney CJ, et al. Association of an educational program in mindful communication with burnout, empathy, and attitudes among primary care physicians. JAMA: Journal of the American Medical Association. 2009; 302:12841293.

Levin, M.; Hayes, SC.; Vilardaga, R. Processes of change in Acceptance and Commitment Therapy: A meta-analysis of mediation in ACT outcome studies. Paper presented at the meeting of the Association for Behavioral and Cognitive Therapies; Orlando, FL. Nov. 2008

Linehan, MM. Cognitive-behavioral treatment for borderline personality disorder. Guilford Press; New York: 1993.

Linehan MM, Armstrong HE, Suarez A, Allman D, Heard HL. Cognitive-behavioral treatment of chronically parasuicidal borderline patients. Archives of General Psychiatry. 1991; 48:1060-1064. [PubMed: 1845222]

Linehan MM, Comtois KA, Murray AM, Brown MZ, Gallop RJ, Heard HL, et al. Two-year randomized controlled trial and follow-up of Dialectical Behavior Therapy vs therapy by experts for suicidal behaviors and borderline personality disorder. Archives of General Psychiatry. 2006; 63:757-766. [PubMed: 16818865]

Luoma, JB.; Hayes, SC.; Walser, RD. Learning ACT: An acceptance and commitment therapy skillstraining manual for therapists. New Harbinger; Oakland, CA: 2007.

Lynch TR, Cheavens JS, Morse JQ, Rosenthal MZ. A model predicting suicidal ideation and hopelessness in depressed older adults: The impact of emotion inhibition and affect intensity. Aging \& Mental Health. 2004; 8:486-497. [PubMed: 15724830]

Maltsberger JT, Buie DH. Countertransference hate in the treatment of suicidal patients. Archives of General Psychiatry. 1974; 30:625-633. [PubMed: 4824197] 
Mean M, Righini NC, Narring F, Jeannin A, Michaud PA. Substance use and suicidal conduct: A study of adolescents hospitalized for suicide attempt and ideation. Acta Paediatrica. 2005; 94:952959. [PubMed: 16188820]

Moscicki EK. Epidemiology of completed and attempted suicide: toward a framework for prevention. Clinical Neuroscience Research. 2001; 1:310-323.

Najmi S, Wegner DM, Nock MK. Thought suppression and self-injurious thoughts and behaviors. Behaviour Research and Therapy. 2007; 45:1957-1965. [PubMed: 17074302]

Neff, KD. Self-Compassion. In: Leary, MR.; Hoyle, RH., editors. Handbook of Individual Differences in Social Behavior. Guilford Press; New York: 2009. p. 561-573.

Neuringer C, Lettieri DJ. Cognition, attitude, and affect in suicidal individuals. Life-Threatening Behavior. 1971; 1:106-124.

Pettit JW, Temple SR, Norton PJ, Yaroslavsky I, Grover KE, Morgan ST, et al. Thought suppression and suicidal ideation: Preliminary evidence in support of a robust association. Depression and Anxiety. 2009; 26:758-763. [PubMed: 18781662]

Pollock LR, Williams JMG. Problem-solving in suicide attempters. Psychological Medicine. 2004; 34:163-167. [PubMed: 14971637]

Roemer L, Borkovec TD. Effects of suppressing thoughts about emotional material. Journal of Abnormal Psychology. 1994; 103:467-474. [PubMed: 7930046]

Sareen J, Houlahan T, Cox BJ, Asmundson GJG. Anxiety disorders associated with suicidal ideation and suicide attempts in the National Comorbidity Survey. The Journal of Nervous and Mental Disease. 2005; 193:450-454. [PubMed: 15985839]

Segal, ZV.; Williams, JMG.; Teasdale, JD. Mindfulness-based cognitive therapy for depression: A new approach to preventing relapse. Guilford Press; New York: 2002.

Shneidman ES. Suicide as psychache. The Journal of Nervous and Mental Disease. 1993; 181:147149.

Siegel, R.; Germer, C.; Olendzki, A. Mindfulness: What is it? Where did it come from?. In: Didonna, F., editor. Clinical handbook of mindfulness. Springer Science+Business Media; New York: 2009. p. 17-35.

Siris SG. Suicide and schizophrenia. Journal of Psychopharmacology. 2001; 15:127-135. [PubMed: 11448086]

Tang NKY, Crane C. Suicidality in chronic pain: A review of the prevalence, risk factors and psychological links. Psychological Medicine. 2006; 36:575-586. [PubMed: 16420727]

Teasdale J, Segal Z, Williams JMG, Ridgeway V, Soulsby J, Lau M. Prevention of relapse/recurrence in major depression by mindfulness-based cognitive therapy. Journal of Consulting and Clinical Psychology. 2000; 68:615-623. [PubMed: 10965637]

Williams, M. Suicide and attempted suicide: Understanding the cry of pain. Penguin Books; London: 2001.

Williams JMG, Barnhofer T, Crane C, Beck AT. Problem solving deteriorates following mood challenge in formerly depressed patients with a history of suicidal ideation. Journal of Abnormal Psychology. 2005; 114:421-431. [PubMed: 16117579]

Williams JM, Broadbent K. Distraction by emotional stimuli: Use of a Stroop task with suicide attempters. The British Journal of Clinical Psychology. 1986; 25:101-110. [PubMed: 3730646]

Williams JMG, Duggan DS, Crane C, Fennell MJV. Mindfulness-based cognitive therapy for prevention of recurrence of suicidal behavior. Journal of Clinical Psychology. 2005; 62:201-210. [PubMed: 16342287]

Williams JMG, Teasdale JD, Segal ZV, Soulsby J. Mindfulness-based cognitive therapy reduces overgeneral autobiographical memory in formerly depressed patients. Journal of Abnormal Psychology. 2000; 109:150-155. [PubMed: 10740947] 